\title{
Optical coherence tomography: high-resolution imaging modality useful in identifying the pathophysiology of coronary vasospasm in acute coronary syndrome
}

\author{
Pramod Kumar Ponna, ${ }^{1}$ Yashwant Agrawal $\quad 0$, ${ }^{2}$ Adnan Kassier, ${ }^{2}$ \\ Jagadeesh K Kalavakunta (1) ${ }^{2}$
}

'Internal Medicine, LSU Health Shreveport, Shreveport, Louisiana, USA

${ }^{2}$ Interventional Cardiology, Ascension Borgess Hospital, Kalamazoo, Michigan, USA

\section{Correspondence to}

Dr Yashwant Agrawal; yashwantagrawal.agrawal@ gmail.com

Accepted 2 May 2021
Check for updates

C) BMJ Publishing Group Limited 2021. No commercial re-use. See rights and permissions. Published by BMJ.

To cite: Ponna PK, Agrawal Y, Kassier $\mathrm{A}$, et al. BMJ Case Rep 2021;14:e242827. doi:10.1136/bcr-2021 242827

\section{DESCRIPTION}

A 39-year-old woman with gastro-oesophageal reflux disease, tobacco abuse and family history of premature coronary artery disease (CAD) presented to the hospital reporting of new onset substernal chest pain for 4 days prior to admission. She experienced multiple episodes of chest pain at rest and exertion without aggravating or alleviating factors. Each episode lasted for $15 \mathrm{~min}$ with radiation to the left arm. Associated symptoms included left arm tingling sensation, diaphoresis, dry mouth, blurry vision and dizziness. Physical examination was unremarkable. Initial vital signs were significant for tachycardia with heart rate in 130 s. ECG showed sinus tachycardia and ST-segment elevations in leads V1, V2 that were transient (figure 1). Serial cardiac biomarkers showed up-trending troponin levels at $2.05 \mathrm{ng} / \mathrm{mL}$ (normal range: $0.00-0.04 \mathrm{ng} /$ $\mathrm{mL}$ ). Patient was started on heparin drip, aspirin, statin, beta-blocker and scheduled for urgent cardiac catheterisation.

Transthoracic echocardiogram revealed a preserved ejection fraction of $60 \%$ without regional wall motion abnormalities. Coronary angiography showed severe $(80 \%-90 \%)$ proximal stenosis of left anterior descending (LAD) with normal left circumflex and right coronary arteries (video 1). Our differential diagnosis included non-ST-segment elevation myocardial infarction (NSTEMI) and coronary vasospasm. An amount of $200 \mu \mathrm{g}$ of intracoronary nitroglycerin was administered in the left coronary system. Repeated coronary angiography after adequate time was given to allow the nitroglycerin to percolate, which revealed persistence of the lesion (video 2). Given these angiographic findings, we decided to proceed with intervention

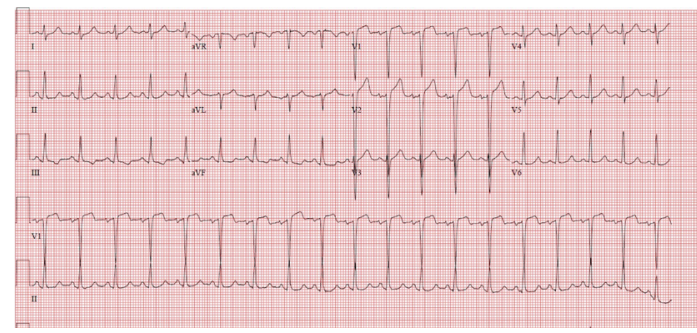

Figure 1 EKG. Transient ST-segment elevations in leads $\mathrm{V} 1$ and $\mathrm{V} 2$.

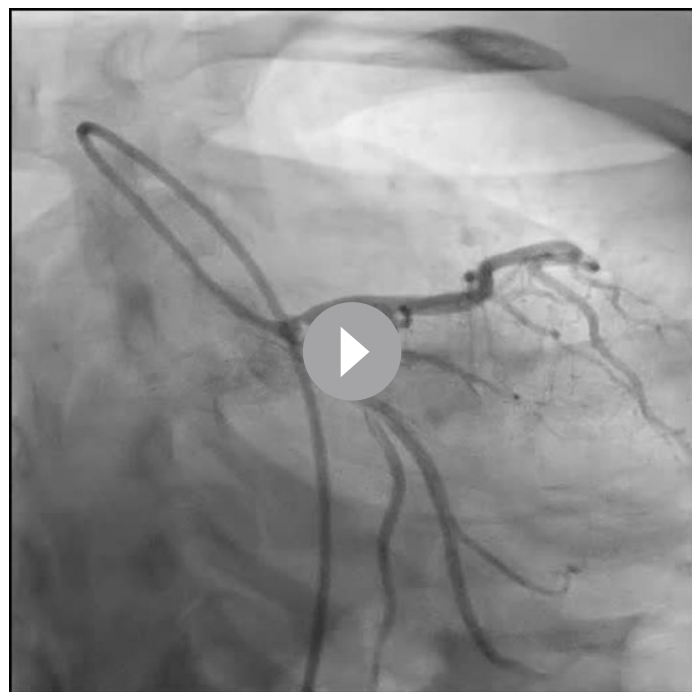

Video 1 AP caudal view. Coronary angiogram. Severe proximal stenosis of LAD. AP, Anterior/Posterior; LAD, left anterior descending.

of the LAD. We first inserted a 7-french XB 3.0 guide catheter into the left coronary artery. As we were inserting a run-through interventional wire

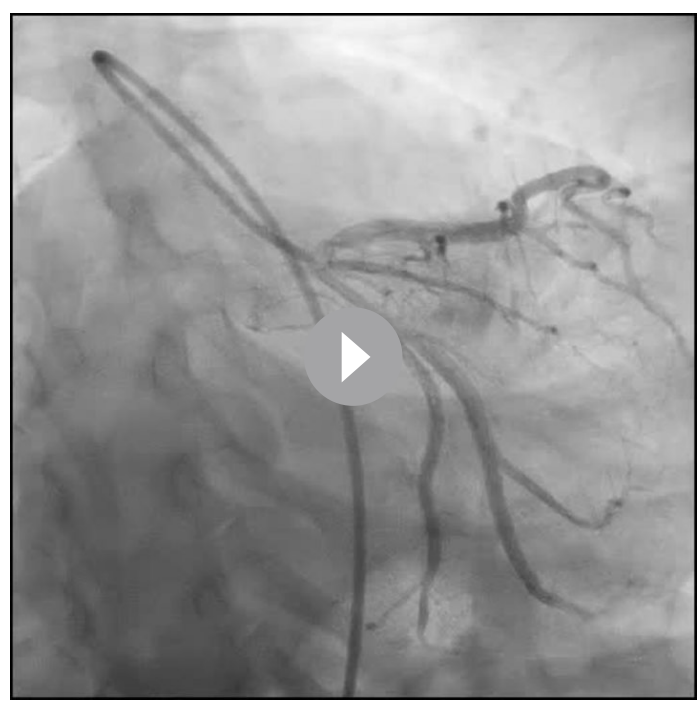

Video 2 AP caudal view. Coronary angiogram. Persistence of the LAD lesion after intracoronary nitroglycerin. $A P$, Anterior/Posterior; $L A D$, left anterior descending. 


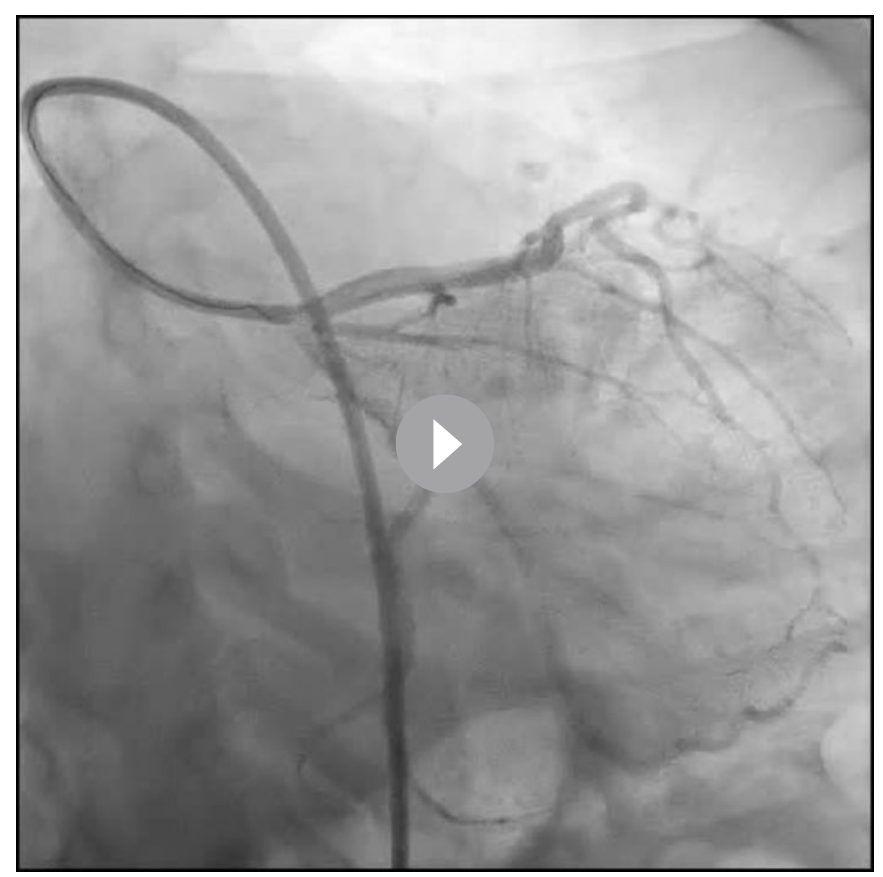

Video 3 AP caudal view. Coronary angiogram. Resolution of LAD lesion. AP, Anterior/Posterior; LAD, left anterior descending.

into the $\mathrm{LAD}$, the lesion was not appreciated anymore in the proximal LAD, hence increasing the suspicion of coronary vasospasm. (video 3). The patient was asymptomatic during cardiac catheterisation. Decision was made to perform optical coherence tomography (OCT)-guided intravascular imaging of the LAD to assess intraluminal pathology in the LAD. OPTicross OCT catheter was inserted and intravascular images of the LAD were obtained, which revealed absence of CAD or plaque rupture in the LAD (video 4). The diagnosis of vasospastic angina (VSA) was, hence, confirmed.

Patient was started on calcium channel blockers. She was strongly advised to quit smoking and has been asymptomatic in outpatient follow-up visits.

OCT can help study pathology of coronary arterial wall at the vasospasm sites in patients with VSA. ${ }^{2}$ Luminal irregularity,

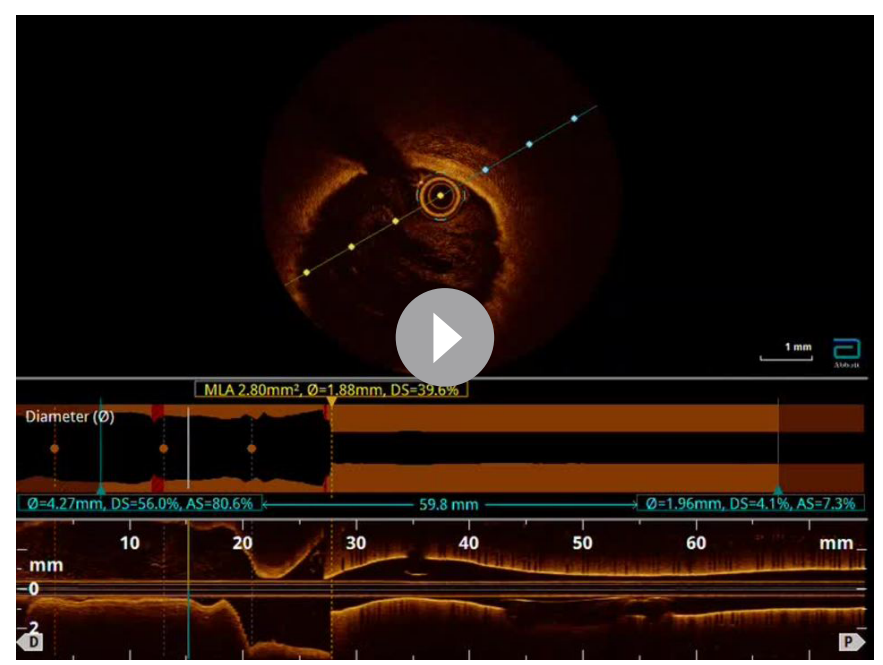

Video 4 Optical coherence tomography. Absence of coronary artery disease or plaque rupture in LAD. LAD, left anterior descending. intraluminal thrombi and intimal erosion are the most common morphological features of coronary artery spasm sites visualised using OCT in patients with VSA. ${ }^{3-6}$ VSA can occur in angiographically normal or near-normal coronary arteries.

Above case represents VSA as the cause for acute coronary syndrome confirmed with OCT, which helped in ruling out atherosclerotic $\mathrm{CAD}$ and plaque rupture. To evaluate culprit lesion, OCT was performed, which helped in confirming the mechanism of acute coronary syndrome in our patient. ${ }^{7}$ Our patient had normal coronary arteries at the vasospasm sites on OCT. Troponin elevation can be seen in both coronary vasospasm and NSTEMI. ${ }^{8}$

\section{Learning points}

- Optical coherence tomography (OCT) can be used to confirm the mechanism of acute coronary syndrome.

- OCT reveals coronary artery wall microstructure at vasospastic sites.

- Coronary vasospasm and non-ST-segment elevation myocardial infarction can both cause elevation of troponin and present with typical features of chest pain.

- Coronary vasospasm is an uncommon presentation of acute coronary syndrome. It is less common than typical angina caused by atherosclerotic disease. It should be one of the leading differentials when younger age group patients present with chest pain.

- Cigarette smoking is a major risk factor in vasospastic angina and coronary artery disease.

Contributors AK rounded on the patient on the general cardiac floor. YA and JKK performed a cardiac catheterisation on the patient. PKP performed the literature search and helped in writing up the case report.

Funding The authors have not declared a specific grant for this research from any funding agency in the public, commercial or not-for-profit sectors.

Competing interests None declared.

Patient consent for publication Obtained.

Provenance and peer review Not commissioned; externally peer reviewed.

\section{ORCID iDs}

Yashwant Agrawal http://orcid.org/0000-0002-1352-583X

Jagadeesh K Kalavakunta http://orcid.org/0000-0003-4635-4616

\section{REFERENCES}

1 Tanaka A, Shimada K, Tearney GJ, et al. Conformational change in coronary artery structure assessed by optical coherence tomography in patients with vasospastic angina. J Am Coll Cardiol 2011;58:1608-13.

2 Ong P, Aziz A, Hansen HS, et al. Structural and functional coronary artery abnormalities in patients with vasospastic angina pectoris. Circ J 2015;79:1431-8.

3 Shin E-S, Ann SH, Singh GB, et al. OCT-Defined Morphological Characteristics of Coronary Artery Spasm Sites in Vasospastic Angina. JACC Cardiovasc Imaging 2015;8:1059-67.

4 Park H-C, Shin JH, Jeong WK, et al. Comparison of morphologic findings obtained by optical coherence tomography in acute coronary syndrome caused by vasospasm and chronic stable variant angina. Int J Cardiovasc Imaging 2015;31:229-37.

5 Park H-C, Choi SI, Lee JU, et al. Morphological findings in typical variant angina presenting as acute coronary syndrome using optical coherence tomography. J Interv Cardiol 2013;26:491-500.

6 Lerman A, Kwon T-G, Lerman LO. Morphological characteristics of coronary arteries in patients with vasospastic angina: another form of atherosclerosis? JACC CardiovasC Imaging 2015;8:1068-70.

7 Kobayashi N, Takano M, Hata N, et al. Optical coherence tomography findings in a case of acute coronary syndrome caused by coronary vasospasm. Int Heart J 2010;51:291-2.

8 Wang C-H, Kuo L-T, Hung M-J, et al. Coronary vasospasm as a possible cause of elevated cardiac troponin I in patients with acute coronary syndrome and insignificant coronary artery disease. Am Heart J 2002;144:275-81. 
Copyright 2021 BMJ Publishing Group. All rights reserved. For permission to reuse any of this content visit https://www.bmj.com/company/products-services/rights-and-licensing/permissions/

BMJ Case Report Fellows may re-use this article for personal use and teaching without any further permission.

Become a Fellow of BMJ Case Reports today and you can:

- Submit as many cases as you like

- Enjoy fast sympathetic peer review and rapid publication of accepted articles

Access all the published articles

Re-use any of the published material for personal use and teaching without further permission

Customer Service

If you have any further queries about your subscription, please contact our customer services team on +44 (0) 2071111105 or via email at support@bmj.com.

Visit casereports.bmj.com for more articles like this and to become a Fellow 